\title{
Distribution of Periodontal Pockets Among Smokers and Nonsmokers in Patients with Chronic Periodontitis: A Cross-sectional Study
}

Surekha Velidandla ${ }^{1}$, Ruparani Bodduru ${ }^{2}$, Vinod Birra ${ }^{3}$, Yash Jain ${ }^{4}$, Rathna Valluri ${ }^{4}$, Kranti Kiran Reddy Ealla ${ }^{1}$

1. Oral and Maxillofacial Pathology, MNR Dental College and Hospital, Hyderabad, IND 2. Periodontology, MNR Dental College and Hospital, Hyderabad, IND 3. Dentistry, Government Medical College, Srikakulam, IND 4. General Dentistry, Malla Reddy Institute of Dental Sciences, Hyderabad, IND

Corresponding author: Kranti Kiran Reddy Ealla, drekkr@yahoo.co.in

\section{Abstract}

\section{Context}

Cigarette smoking is a well-established risk factor for periodontitis and carries an increased risk for loss of periodontal attachment as well as bone loss.

\section{Aims}

The purpose of the present study was to investigate whether disease severity differs between smokers and nonsmokers in a group of chronic periodontitis patients by assessing the periodontal probing depth (PPD) and bleeding on probing (BOP).

\section{Materials and methods}

The study included 150 individuals, 75 smokers and 75 nonsmokers, in the age group of 35-60 years. Subjects with chronic periodontitis were selected and included in the study. Periodontal evaluation, including periodontal probing pocket depths and bleeding on probing, was performed on all four quadrants and at six sites per tooth using the Williams periodontal probe. The data were pooled from the anterior sextant and the posterior sextant as well as from the facial and lingual surfaces.

\section{Statistical analysis}

Comparisons were made between smokers and nonsmokers using the z-test (two-tailed test). Probing pocket depth categories 0-3 mm, 4-5 mm, 6-7 mm, and $\geqslant 8 \mathrm{~mm}$ and the proportion of sites having a pocket depth of $\geqslant 5 \mathrm{~mm}$ were used in the analysis.

Received 08/29/2019

Review began 09/03/2019 Review ended 09/04/2019 Published 09/06/2019

\section{() Copyright 2019}

Velidandla et al. This is an open access article distributed under the terms of the Creative Commons Attribution License CC-BY 3.0., which permits unrestricted use, distribution, and reproduction in any medium, provided the original author and source are credited.

\section{Results}

The mean percentage of sites that bleed upon probing was higher for nonsmokers as compared with smokers. Smokers had less shallow pockets $(0-3 \mathrm{~mm})$ than nonsmokers and more pockets of 4-7 mm (categories 4-5 mm, 6-7 mm). No significant differences were detected in the prevalence of pockets $\geqslant 8 \mathrm{~mm}$. In the anterior, premolar, and molar regions, pockets of 6-7 $\mathrm{mm}$ were significantly more prevalent in smokers. The buccal and lingual sides also showed that smokers had more sites with deep probing depths $\geqslant 5$ $\mathrm{mm}$ than nonsmokers. The data also showed that in the upper jaw, in the anterior and premolar teeth, the largest differences were found between smokers and nonsmokers.

\section{Conclusions}

From the results, it can be concluded that cigarette smoking results in periodontal tissue destruction in the different areas of the oral cavity, with the maximum periodontal destruction in the maxillary anterior and premolar region.

Categories: Pain Management, Pathology, Dentistry

Keywords: bleeding on probing, periodontal pocket depth, periodontitis, smoking

\section{Introduction}

Periodontitis is the result of complex interrelationships between infectious agents and host factors. Environmental, acquired, and genetic risk factors modify the expression of disease and may, therefore, affect the onset or progression of periodontitis [1]. Among the environmental risk factors, tobacco smoking has been found to be associated with an increased prevalence and severity of periodontal disease [2]. It is also apparent that a disproportionately high number of people with severe periodontal disease are smokers [3] 
and that a strong association exists between smoking and an unusual form of periodontitis that is resistant to treatment.

In a study evaluating the effect of nonsurgical treatment in smokers and nonsmokers, the degree of pocket reduction was significantly lower in smokers. The strongest difference was observed for pockets of the maxillary anterior region [4], a finding also suggestive of local effects. Furthermore, this local effect is also substantiated by the observation that smokers, in general, have proportionately more periodontal pocketing in the anterior segments than those who have never smoked $[2,5]$. The purpose of the present study was to investigate whether the disease severity differs between smokers and nonsmokers in a group of chronic periodontitis patients.

\section{Materials And Methods}

The present study was conducted in the department of periodontology, MNR Dental College and Hospital, Sangareddy, Hyderabad, India. The sample size of the study was 150 individuals, with 75 smokers, and 75 nonsmokers in the age group of 35-60 years. Subjects with chronic periodontitis were selected and included in the study. Periodontal evaluation, including periodontal probing pocket depths and bleeding on probing, was performed on all four quadrants and at six sites per tooth using the Williams periodontal probe. Patients who were systemically healthy with chronic periodontitis and smokers who smoke $\geqslant 10$ cigarettes daily for $\geqslant 10$ years were included in the study. Patients who underwent periodontal therapy and who were on antibiotic therapy were excluded.

For both parameters (probing pocket depth, bleeding on probing), full mouth mean scores were calculated, as well as scores considering the upper jaw, lower jaw, buccal, lingual, anteriors, premolars, and molars. Probing pocket depth categories $0-3 \mathrm{~mm}, 4-5 \mathrm{~mm}, 6-7 \mathrm{~mm}$, and $\geqslant 8 \mathrm{~mm}$ and the proportion of sites having a pocket depth of $\geqslant 5 \mathrm{~mm}$ were used in the analysis. Comparisons were made between smokers and nonsmokers using the z-test (two-tailed test).

\section{Results}

Mean age, mean number of teeth, and mean percent of sites did not differ between smokers and nonsmokers (Table 1). The mean percent of sites that bleed upon probing was higher for nonsmokers as compared to smokers. Smokers had less shallow pockets $(0-3 \mathrm{~mm})$ than nonsmokers and more pockets $(4-7 \mathrm{~mm}$; categories 4-5 mm, 6-7 mm). No significant differences were detected in the prevalence of pockets $\geqslant 8 \mathrm{~mm}$. In the anterior, premolar, and molar regions, pockets of 6-7 mm were significantly more prevalent in smokers (Table 2). The overall differences in the prevalence of probing depths $\geqslant 5 \mathrm{~mm}$ between smokers and nonsmokers were $48 \%$ and $37 \%$, respectively (Table 3 ). In the upper jaw, $48 \%$ of the sites in smokers were $\geqslant 5$ $\mathrm{mm}$ while $37 \%$ of the sites in non-smokers showed probing depths $\geqslant 5 \mathrm{~mm}$. The buccal and lingual sides also showed that smokers had more sites with deep probing depths $\geqslant 5 \mathrm{~mm}$ than nonsmokers. The data also showed that in the upper jaw, in the anterior and premolar teeth, the largest differences were found between smokers and nonsmokers. Smokers had proportionally more pockets $\geqslant 5 \mathrm{~mm}$, especially on the palatal and lingual surfaces (Table 4). 


\section{Cureus}

\begin{tabular}{|c|c|c|c|}
\hline & Nonsmokers & Smokers & z-test \\
\hline $\mathrm{n}$ & 75 & 75 & \\
\hline Age (years) & $47(8)$ & $46(6)$ & ns \\
\hline Mean \# of teeth & $25(3.6)$ & $25.7(3.8)$ & ns \\
\hline Anterior & $11.1(1.5)$ & $11.1(1.2)$ & ns \\
\hline Premolars & $7.7(1.6)$ & $7.9(1.7)$ & ns \\
\hline Molars & $7.5(2.8)$ & $7.2(2.8)$ & ns \\
\hline \multicolumn{4}{|c|}{$\%$ distribution of probing pocket depth (PPD) categories } \\
\hline \%PPD 0-3mm & 48.6 (19.5) & $36.8(5.9)$ & $* \star$ \\
\hline \%PPD 4-5mm & $37.7(12.9)$ & 39.3 (12.3) & ns \\
\hline \%PPD 6-7mm & $15.2(8.2)$ & $22.2(10.2)$ & $* *$ \\
\hline$\% \mathrm{PPD} \geq 8 \mathrm{~mm}$ & $9.2(6.5)$ & $10.2(5.6)$ & ns \\
\hline
\end{tabular}

TABLE 1: Number of teeth, mean $\%$ of sites showing bleeding upon probing by location, and $\%$ oral distribution of probing pocket depth (PPD) categories, presented by smoking status; standard deviation in parentheses.

z-test between nonsmokers and smokers; ns represents there is no significant difference between the two variables; ${ }^{\star \star}$ represents a significant difference between two variables at a $5 \%$ level of significance 


\section{Cureus}

\begin{tabular}{|c|c|c|c|}
\hline & Nonsmokers & Smokers & z-value \\
\hline \multicolumn{4}{|l|}{ Anterior } \\
\hline \%PPD 0-3mm & $56(22)$ & 41 (19) & ** \\
\hline \%PPD 4-5mm & 31 (15) & $38(16)$ & ** \\
\hline \%PPD 6-7mm & $10(12)$ & 16 (15) & $\star \star *$ \\
\hline$\%$ PPD $\geq 8$ mm & $5(7)$ & $6(9)$ & ns \\
\hline \multicolumn{4}{|l|}{ premolars } \\
\hline \%PPD 0-3mm & $44(18)$ & $34(15)$ & ** \\
\hline \%PPD 4-5mm & $38(14)$ & $40(15)$ & ns \\
\hline \%PPD 6-7mm & $14(8)$ & 20(13) & $\star \star *$ \\
\hline \%PPD $\geq 8$ mm & $6(8.5)$ & $7(9)$ & ns \\
\hline \multicolumn{4}{|l|}{ Molars } \\
\hline \%PPD 0-3mm & $22(14.5)$ & $15(9.5)$ & $\star \star *$ \\
\hline \%PPD 4-5mm & 42(17) & $43(16)$ & ns \\
\hline \%PPD 6-7mm & 20(15) & $35(14)$ & ** \\
\hline \%PPD $\geq 8 \mathrm{~mm}$ & $18(14.5)$ & $14(12)$ & ns \\
\hline
\end{tabular}

TABLE 2: Percent oral distribution of probing pocket depth categories presented by smoking status (nonsmokers, $n=75 /$ smokers, $n=75$ ); standard deviation in parentheses

z-test between non smokers and smokers; ns represents there is no significant difference between two variables; ** represents a significant difference between two variables at a $5 \%$ level of significance

\begin{tabular}{|c|c|c|c|}
\hline & Nonsmokers & Smokers & z-value \\
\hline All sites & 37 (19) & $48(17)$ & ** \\
\hline Anterior & $25(20)$ & $34(22)$ & ** \\
\hline Premolars & $35(23)$ & $45(21)$ & $\star \star$ \\
\hline Molars & $54(21)$ & 63(16) & ** \\
\hline
\end{tabular}

TABLE 3: Percent of sites with a probing pocket depth $\geq 5 \mathrm{~mm}$ presented by location and by smoking status (nonsmokers, $n=75 /$ smokers, $n=75$ ); standard deviation in parentheses

z-test between nonsmokers and smokers; ns represents there is no significant difference between the two variables; ** represents there is a significant difference between the two variables at the $5 \%$ level of significance

\begin{tabular}{|c|c|c|c|}
\hline & Nonsmokers & Smokers & z-value \\
\hline \multicolumn{4}{|l|}{ Upper jaw } \\
\hline All sites & $35(20)$ & $46(18)$ & $\star \star$ \\
\hline Anterior & $26(24)$ & $39(24)$ & $\star \star$ \\
\hline Premolars & $38(27)$ & $51(21)$ & ** \\
\hline Molars & $56(22)$ & 65(18) & $\star \star \star ~$ \\
\hline
\end{tabular}




\section{Cureus}

\begin{tabular}{|c|c|c|c|}
\hline \multicolumn{4}{|l|}{ Lower jaw } \\
\hline All sites & $30(20)$ & $40(19)$ & ** \\
\hline Anterior & $23(22)$ & $34(21)$ & 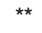 \\
\hline Premolars & $29(24)$ & $37(22)$ & ** \\
\hline Molars & $54(23)$ & $65(19)$ & ** \\
\hline \multicolumn{4}{|l|}{ Buccal } \\
\hline All sites & $30(19)$ & $41(18)$ & $\star *$ \\
\hline Anterior & $24(22)$ & $35(22)$ & ** \\
\hline Premolars & $29(22)$ & $36(21)$ & ** \\
\hline Molars & $54(25)$ & $60(19)$ & ** \\
\hline \multicolumn{4}{|l|}{ Lingual } \\
\hline All sites & $39(22)$ & $49(20)$ & ** \\
\hline Anterior & $25(24)$ & $35(24)$ & ** \\
\hline Premolars & $38(25)$ & $55(23)$ & ** \\
\hline Molars & $58(23)$ & $67(19)$ & ** \\
\hline \multicolumn{4}{|c|}{ Upper jaw buccal } \\
\hline All sites & $40(24)$ & $55(22)$ & ** \\
\hline Anterior & $30(30)$ & $45(30)$ & ** \\
\hline Premolars & $43(28)$ & $57(24)$ & ** \\
\hline Molars & $59(26)$ & $66(22)$ & ** \\
\hline \multicolumn{4}{|c|}{ Lower jaw buccal } \\
\hline All sites & $30(22)$ & $39(28)$ & ** \\
\hline Anterior & $22(24)$ & $33(25)$ & ** \\
\hline Premolars & $24(26)$ & 29(22) & ** \\
\hline Molars & $49(27)$ & $60(23)$ & ** \\
\hline \multicolumn{4}{|c|}{ Lower jaw lingual } \\
\hline All sites & $35(22)$ & $44(21)$ & ** \\
\hline Anterior & $18(27)$ & $26(23)$ & ** \\
\hline Premolars & $35(27)$ & $50(31)$ & ** \\
\hline Molars & $61(28)$ & $67(26)$ & ** \\
\hline \multicolumn{4}{|c|}{ Upper jaw palatal } \\
\hline All sites & $42(26)$ & $56(24)$ & ** \\
\hline Anterior & $31(30)$ & 44(28) & $\star \star \star ~$ \\
\hline Premolars & $44(31)$ & $57(24)$ & ** \\
\hline Molars & $57(27)$ & 68(24) & ** \\
\hline
\end{tabular}

TABLE 4: Percent of sites with a probing pocket depth $\geq 5 \mathrm{~mm}$ presented by location and by smoking status standard deviation in parentheses

z-test between nonsmokers and smokers; ns represents there is no significant difference between the two variables; ** represents there is a significant difference between the two variables at the $5 \%$ level of significance 
Data were further analyzed by dividing the smokers into two subgroups based on cigarette consumption. The mean proportion of pockets $\geqslant 5 \mathrm{~mm}$ was higher for those who smoked $\geqslant 20$ cigarettes per day than those who smoked 11-20 cigarettes.

\section{Discussion}

The present study investigated whether cigarette smoking affects the extent of pocketing and bleeding on probing in chronic periodontitis patients. Bleeding upon probing (BOP) provides a quantitative indication of gingival/periodontal inflammation. BOP acts as diagnostic predictability, as bleeding on probing and loss of attachment are interrelated [6]. Smokers presented with reduced signs of inflammation as compared to nonsmokers, which is expressed on bleeding on probing [7-8]. The decreased bleeding among smokers can be attributed to the temporary gingival vasoconstriction induced by nicotine. It is also suggested that swollen gingiva in smokers represent decreased vascularity density and angiogenesis as compared to nonsmokers, which is due to the suppressed inflammatory response [9]. Cigarette smoke comprises many components that can alter the function of immune cells [10-11].

Smokers had fewer sites with bleeding on probing as compared with nonsmokers. Most investigators had found that smokers had less bleeding on provocation than nonsmokers, although one study reported smokers had more bleeding $[2,12]$. Another study reported no differences were found between smokers and nonsmokers [13]. Decreased gingival bleeding in smokers had been explained as being due to nicotine, which causes vasoconstriction of peripheral blood vessels such as in the forearm, skin, and hands [14].

Nicotine can cause a dose-dependent inhibition on type 1 collagen production and fibronectin production. There is an increase in the collagenase activity, which equals to an approximately $700 \%$ and $400 \%$ increase per $0.075 \%$ and $0.05 \%$ of nicotine concentration [15].

Several studies had shown a relationship between the number of cigarettes smoked and the prevalence and severity of periodontitis [16-20]. Patients smoking more than 10 cigarettes per day or smoking more than 10 years were relatively more frequent in the moderate to advanced periodontitis group, whereas those smoking less or for a shorter duration were not [5]. Smoking impairs chemotaxis, decreases phagocytosis by neutrophils, and reduces antibody production, resulting in detrimental effects on the periodontium [21-22]. The effect of vasoconstriction and decreased oxygen tension create a compatible subgingival environment for the colonization of anaerobic bacteria [23]. Many studies have proved the pattern of periodontal destruction among smokers, considering the local effect of smoking on the palatal surfaces or on the maxillary anterior region [24-26]. The difference in patterns of pocketing in smokers and nonsmokers was suggestive of a local effect. The present study showed that the proportion of pockets $\geqslant 5 \mathrm{~mm}$ did differ in almost all instances. Data were separated by upper and lower jaw, buccal and lingual surfaces, and tooth type. In the upper jaw, in the anterior and premolar teeth, the largest differences were found between smokers and nonsmokers. Smokers have more sites with pocket depth $\geqslant 5 \mathrm{~mm}$, especially on the lingual surface of these teeth. The probing depth categories showed that smokers had primarily less shallow pockets and more pockets between $4 \mathrm{~mm}$ and $7 \mathrm{~mm}$. The difference between smokers and nonsmokers was most pronounced in the anterior region. These observations correlate with earlier findings $[5,13]$ and were suggestive of a local effect.

\section{Conclusions}

In conclusion, the present study indicates that cigarette smoke has many components associated with deeper periodontal pockets in association with impaired immunological response. The pocket severity also follows an intraoral distribution pattern, which is related to the local effect of smoke, altering the local temperature and favoring plaque formation. The implications of this are that efforts at smoking cessation should be considered in the treatment of periodontitis. Furthermore, prevention and counseling should be part of community education for the purpose of preventing periodontal diseases. By acquiring tobacco intervention skills, dentists, hygienists, and assistants can take a leading role among health professionals in having a significant impact on the negative health effects associated with the use of tobacco products.

\section{Additional Information \\ Disclosures}

Human subjects: Consent was obtained by all participants in this study. MNR Dental College and Hospital issued approval ECR/269/Indt/TG/2016. CERTIFICATE FROM THE ETHICAL COMMITTEE AND INSTITUTIONAL RESEARCH BOARD Document for Institutional Ethical Clearance Institution Ethical Committee Reg. No: ECR/269/Indt/TG/2016 Title: DISTRIBUTION OF PERIODONTAL POCKETS AMONG SMOKERS AND NON- SMOKERS IN PATIENTS WITH CHRONIC PERIODONTITIS: A CROSS-SECTIONAL STUDY Name of the Principal Investigator: Surekha Velidandla Course: MDS Date: 25-6-2018 The above proposal has been reviewed by the ethical committee and the committee recommends that the project be approved. Animal subjects: All authors have confirmed that this study did not involve animal subjects or tissue. Conflicts of interest: In compliance with the ICMJE uniform disclosure form, all authors declare the following: Payment/services info: All authors have declared that no financial support was received from 
any organization for the submitted work. Financial relationships: All authors have declared that they have no financial relationships at present or within the previous three years with any organizations that might have an interest in the submitted work. Other relationships: All authors have declared that there are no other relationships or activities that could appear to have influenced the submitted work.

\section{References}

1. Page RC, Offenbacher S, Schroeder HE, Seymour GJ, Kornman KS: Advances in the pathogenesis of periodontitis: summary of developments, clinical implications and future directions. Periodontol 2000. 2007, 14:216-248. 10.1111/j.1600-0757.1997.tb00199.x

2. Haber J, Wattles J, Crowley M, Mandell R, Joshipura K, Kent RL: Evidence for cigarette smoking as a major risk factor for periodontitis. J Periodontol. 1993, 64:16-23. 10.1902/jop.1993.64.1.16

3. Bergstrom J: Cigarette smoking as risk factor in chronic periodontal disease . Community Dent Oral Epidemiol. 1989, 17:245-247.

4. Preber H, Bergstrom J: The effect of non-surgical treatment on periodontal pockets in smokers and nonsmokers. J Clin Periodontol. 1986, 13:319-323.

5. Haber J, Kent RL: Cigarette smoking in a periodontal practice . J Periodontol. 1992, 63:100-106. 10.1902/jop.1992.63.2.100

6. Al-Bayaty FH, Baharuddin NA, Abdulla MA, Mohd Ali H, Arkilla MB, ALBayaty MF: The influence of cigarette smoking on gingival bleeding and serum concentrations of haptoglobin and alpha 1-antitrypsin. Biomed Res Int. 2013, 2013:684154. 10.1155/2013/684154

7. Haffajee AD, Socransky SS: Relationship of cigarette smoking to attachment level profiles [Article in German]. J Clin Periodontol. 2001, 28:283-295. 10.1034/j.1600-051x.2001.028004283.x

8. Müller HP, Heinecke A, Eger T: Site-specific association between supragingival plaque and bleeding upon probing in young adults. Clin Oral Investig. 2000, 4:212-218. 10.1007/s007840000078

9. Bergström J, Persson L, Preber H: Influence of cigarette smoking on vascular reaction during experimental gingivitis. Scand J Dent Res. 1988, 96:34-39. 10.1111/j.1600-0722.1988.tb01405.x

10. Sopori M: Effects of cigarette smoke on the immune system . Nat Rev Immunol. 2002, 5:372-377. 10.1038/nri803

11. Adamson J, Thorne D, McAughey J, Dillon D, Meredith C: Quantification of cigarette smoke particle deposition in vitro using a triplicate quartz crystal microbalance exposure chamber. Biomed Res Int. 2013, 2013:685074. 10.1155/2013/685074

12. Newbrun E: Indices to measure gingival bleeding. J Periodontol. 1996, 67:555-561. 10.1902/jop.1996.67.6.555

13. van der Weijden GA, de Slegte C, Timmerman MF, van der Velden U: Periodontitis in smokers and nonsmokers: intra-oral distribution of pockets [Article in German]. J Clin Periodontol. 2001, 28:955-960.

14. Larson PS, Silvette H: Tobacco. Experimental and Clinical Studies (Supplement III). PS Larson, HB Haag, H Silvette (ed): The Williams \& Wilkins Co, Baltimore, US; 1961. 10.1002/jps.2600500421

15. Chahal GS, Chhina K, Chhabra V, Chahal A: Smoking and its effect on periodontium - revisited . Indian J Dent Sci. 2017, 9:44-51. 10.4103/IJDS.IJDS_96_16

16. Grossi SG, Genco RJ, Machtei EE, et al.: Assessment of risk for periodontal disease. II. Risk indicators for alveolar bone loss. J Periodontol. 1995, 66:23-29. 10.1902/jop.1995.66.1.23

17. Martinez-Canut P, Lorca A, Magán R: Smoking and periodontal disease severity . J Clin Periodontol. 1995, 22:743-749. 10.1111/j.1600-051X.1995.tb00256.x

18. González YM, De Nardin A, Grossi SG, Machtei EE, Genco RJ, De Nardin E: Serum cotinine levels, smoking, and periodontal attachment loss. J Dent Res. 1996, 75:796-802. 10.1177/00220345960750021001

19. Krall EA, Dawson-Hughes B, Garvey AJ, Garcia RI: Smoking, smoking cessation, and tooth loss . J Dent Res. 1997, 76:1653-1659. 10.1177/00220345970760100601

20. Tomar SL, Asma S: Smoking-attributable periodontitis in the United States: findings from NHANES III . J Periodontol. 2000, 71:743-751. 10.1902/jop.2000.71.5.743

21. Persson L, Bergstrom J, Ito H, Gustafsson A: Tobacco smoking and neutrophil activity in patients with periodontal disease. J Periodontol. 2001, 72:90-95. 10.1902/jop.2001.72.1.90

22. Palmer RM, Wilson RF, Hasan AS, Scott DA: Mechanisms of action of environmental factors - tobacco smoking. J Clin Periodontol. 2005, 32:180-195. 10.1111/j.1600-051X.2005.00786.x

23. Salvi GE, Lawrence HP, Offenbacher S, Beck JD: Influence of risk factors on the pathogenesis of periodontitis. Periodontol 2000. 1997, 14:173-201. 10.1111/j.1600-0757.1997.tb00197.x

24. Haber J: Smoking is a major risk factor for periodontitis . Curr Opin Periodontol. 1994, 12:18.

25. Axelsson P, Paulander J, Lindhe J: Relationship between smoking and dental status in 35-, 50-, 65- and 75year-old individuals. J Clin Periodontol. 1998, 25:297-305.

26. van der Weijden GA, de Slegte C, Timmerman MF, van der Velden U: Periodontitis in smokers and nonsmokers: intra-oral distribution of pockets [Article in German]. J Clin Periodontol. 2001, 28:955-960. 